\title{
Liver-only metastatic colorectal cancer patients and thymidylate synthase polymorphisms for predicting response to 5-fluorouracil-based chemotherapy
}

\author{
F Graziano*, I,7, A Ruzzo ${ }^{2,7}$, F Loupakis ${ }^{3}$, D Santini ${ }^{4}$, V Catalano', E Canestrari' ${ }^{2}$, P Maltese ${ }^{2}$, R Bisonni $^{5}$,

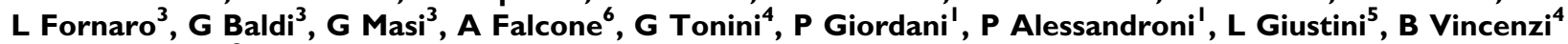 \\ and $M$ Magnani ${ }^{2}$ \\ 'Medical Oncology, Azienda Ospedaliera 'Ospedale San Salvatore', Pesaro, Italy; ${ }^{2}$ Institute of Biochemistry 'G Fornaini', University of Urbino, Urbino, Italy; \\ ${ }^{3}$ Medical Oncology, Hospital of Livorno, Livorno, Italy; ${ }^{4}$ Medical Oncology, University Campus Biomedico, Rome, Italy; ${ }^{5}$ Medical Oncology, Hospital of \\ Fermo, Fermo, Italy; ${ }^{6}$ Medical Oncology, Hospital of Livorno and University of Pisa, Pisa, Italy
}

We investigated the association between thymidylate synthase (TS) germline polymorphisms and response to 5-fluorouracil-based chemotherapy in 80 patients with liver-only metastatic colorectal cancer (MCRC). The tandem repeat polymorphism (VNTR) in TS $5^{\prime}$-untranslated region (5'-UTR), which consists of two (2R) or three (3R) 28-bp repeated sequences, with or without a G/C nucleotide change in $3 R$ carriers ( $3 G$ or $3 C$ ) and a 6-bp insertion/deletion $(6+16-)$ in the TS $3^{\prime}-U T R$, was studied. The distinction between high $(2 R / 3 G, 3 C / 3 G$ and $3 G / 3 G)$ and low $(2 R / 2 R, 2 R / 3 C$ and $3 C / 3 C)$ TS expression genotypes according to the $5^{\prime}-U T R$ $\mathrm{VNTR}+\mathrm{G} / \mathrm{C}$ nucleotide change showed significant association with tumour response $(P=0.0 \mathrm{I})$. In particular, high TS expression genotypes were found in 8 out of 34 patients (23.5\%) with complete or partial response and in 24 out of 46 patients (52\%) with stable disease and disease progression. Liver-only MCRC patients are a homogeneous and clinical relevant subgroup that may represent an ideal setting for studying the actual influence of TS polymorphisms.

British Journal of Cancer (2008) 99, 716-721. doi:10.1038/sj.bjc.6604555 www.bjcancer.com

Published online 12 August 2008

(c) 2008 Cancer Research UK

Keywords: colorectal cancer; liver metastasis; thymidylate synthase; polymorphisms; 5-fluorouracil; pharmacogenetics

Functional polymorphisms in the $5^{\prime}$-untranslated region ( $5^{\prime}$-UTR) and the $3^{\prime}$-UTR of the thymidylate synthase (TS) gene have been identified in the last decade (Marsh, 2005). A variable number of 28-bp tandem repeated sequence (VNTR) in TS 5'-UTR determines two $(2 R)$ or three $(3 R)$ alleles (Horie et al, 1995) and three common genotypes $(2 R / 2 R, 2 R / 3 R$ and $3 R / 3 R)$. Upregulated TS protein levels were found to be associated with the $3 R$ allele (Kawakami et al, 1999; Yu et al, 2008). A $G / C$ single-nucleotide polymorphism (SNP) in the $3 R$ allele was found to determine two additional alleles ( $3 G$ or $3 C$ ) at this locus (Kawakami and Watanabe, 2003; Mandola et al, 2003), and according to their functional role, it allows a distinction between high $(2 R / 3 G, 3 C / 3 G$ and $3 G / 3 G)$ and low $(2 R /$ $2 R, 2 R / 3 C$ and $3 C / 3 C$ ) TS expression genotypes in vivo (Morganti et al, 2005; Yawata et al, 2005). A more recently discovered TS genetic variant is a 6 -bp insertion/deletion $(6+/ 6)$ in $3^{\prime}$-UTR (Ulrich et al, 2000). TS $3^{\prime}$-UTR genotypes $(6+/ 6+-, 6+/ 6-$ and $6-/ 6-)$ seem to be associated with variable TS mRNA levels (Mandola et al, 2004); however, the functional effect of the $3^{\prime}$-UTR polymorphism is not well defined yet (Calascibetta et al, 2004).

*Correspondence: Dr F Graziano, Department of Onco-Hematology, Azienda Ospedaliera 'Ospedale San Salvatore', 6I 100 Pesaro, Italy;

E-mail: frada@tin.it

${ }^{7}$ These authors contributed equally to this study.

Received 23 April 2008; revised 2 July 2008; accepted 7 July 2008; published online 12 August 2008
5-Fluorouracil is a fundamental drug in the treatment of patients with colorectal cancer, and TS levels are considered an important factor for explaining the differences in 5-fluorouracil antitumour activity (Popat et al, 2004). Therefore, the TS functional polymorphisms are under investigation for the possibility of optimising chemotherapy (Yong and Innocenti, 2007). Studies in patients with metastatic colorectal cancer showed that carriers of the TS $5^{\prime}$-UTR $3 R(3 G)$ and/or the TS $3^{\prime}$-UTR $6+$ alleles had adverse clinical outcomes (Pullarkat et al, 2001; Etienne et al, 2002; Park et al, 2002; Marcuello et al, 2004; Stoehlmacher et al, 2004; Martinez-Balibrea et al, 2007); however, such an association was not always detected (Lecomte et al, 2004; Jakobsen et al, 2005; Ruzzo et al, 2007a,b). Heterogeneity in clinical experimental conditions (Sorbye et al, 2007), in tumour burden (Köhne et al, 2002) and in genetic/molecular features in the presence of a multisite metastatic disease (Yokota, 2000) may explain variable results in these pharmacogenetic studies.

We hypothesised that the $20-30 \%$ of patients with liver-only metastatic colorectal cancer (MCRC) (Mandalà et al, 2007) may represent a favourably homogeneous and clinically relevant setting for evaluating the role of TS polymorphisms for predicting response to 5-fluorouracil-based chemotherapy. For this purpose, we performed an analysis of TS polymorphisms in patients with liver-only MCRC who were previously enrolled in two prospective pharmacogenetic studies including 312 patients treated with first-line FOLFOX (bolus/infusional 5-fluorouracil coupled with 
oxaliplatin) or FOLFIRI (bolus/infusional 5-fluorouracil coupled with irinotecan) regimens (Ruzzo et al, 2007a,b). FOLFOX and FOLFIRI regimens are equally active and they produce comparable response rates in first-line chemotherapy. In both the regimens, 5 -fluorouracil is used at the same dose and schedule (Colucci et al, 2005). The primary end point of the study was the association between TS polymorphism and tumour response.

\section{MATERIALS AND METHODS}

\section{Study population}

Three hundred and twelve patients with metastatic colorectal cancer were prospectively enrolled in two previous pharmacogenetic studies (Ruzzo et al, 2007a, b) and they underwent first-line chemotherapy including leucovorin $100 \mathrm{mg} \mathrm{m}^{-2}$ administered as a 2-h infusion before 5-fluorouracil $400 \mathrm{mg} \mathrm{m}^{-2}$ administered as an intravenous bolus injection and 5-fluorouracil $600 \mathrm{mg} \mathrm{m}^{-2}$ as a 22-h infusion immediately after FU bolus injection on days 1 and 2 , every 2 weeks. Eighty patients $(25.6 \%)$ had liver-only metastatic disease and they were included in this analysis. Ten of the 80 patients had history of liver surgery for metastasectomy and they were with liver-only relapse.

The 80 studied patients had cytologically or histologically confirmed metastatic colorectal cancer and the presence of at least one measurable lesion. Pretreatment evaluation included a complete medical and clinical-physical examination, KPS evaluation, baseline measurement of tumour size based on CT scan, serum chemistries and CEA. Objective response was evaluated after four cycles of treatment and then every 2 months according to the RECIST criteria (Therasse et al, 2000). For the purpose of this study, radiology studies of the 80 patients were reviewed for confirming the treatment outcomes. Patients' characteristics and their outcomes were unknown to investigators performing genetic analyses. The study was approved by local ethical committees and patients provided signed informed consent.

\section{Analysis of polymorphisms}

A blood sample from each enrolled patient was used for genotyping and it was collected before starting chemotherapy. Genomic DNA was extracted from $200 \mu$ l whole blood using the QiaAmp kit (Qiagen, Valencia, CA, USA). All polymorphisms were investigated using a PCR-restriction fragment length polymorphism technique. The assays for studying polymorphisms were performed as described previously (Ruzzo et al, 2007a, b).

\section{Statistical analyses}

The primary end point of the study was the association between TS polymorphisms in patients with liver-only MCRC and response to 5-fluorouracil-based chemotherapy. Genotype frequencies were checked for agreement with those expected under the HardyWeinberg equilibrium. Genotypes for each polymorphism were analysed as three-group categorical variable in a codominant model and they were also grouped according to the recessive and additive model. Patients were categorised as responders (patients with complete or partial response) and non-responders (patients with stable disease or disease progression). The $\chi^{2}$-test was used for comparing proportions. Statistical significance was defined as $P<0.05$. A Bonferroni correction of the $P$-value for multiple comparisons was used where applicable.

The SHEsis software platform (http://202.120.7.14/analysis/ myAnalysis.php) was used to estimate haplotype frequencies and the presence of linkage disequilibrium (LD). Linkage disequilibrium exists between two SNPs, if their variants appear together more often than expected (non-random inheritance). Linkage disequilibrium was estimated using $r^{2}$, with $r^{2}=1$ indicating complete LD and $r^{2}=0$ indicating absent LD. Haplotype frequencies were reconstructed in the study population of responders and non-responders. Association of haplotypes with clinical outcome was estimated by comparing haplotype distributions among dichotomised patients using the $\chi^{2}$-test.

\section{RESULTS}

The characteristics of the 80 studied patients and the overall frequencies of genotypes are shown in Table 1. All patients were assessable for response and they received a minimum of four cycles of chemotherapy. In the 80 patients, there was one complete response $(1.2 \%), 33$ partial responses $(41.2 \%), 30$ stable diseases $(37.6 \%)$ and 16 progressions (20\%). Median age was 63 years (minimum 38 years and maximum 75 years). Liver metastases were synchronous in 22 patients $(27.5 \%)$ and metachronous in 68 patients $(72.5 \%)$. The frequencies of genotypes are in HardyWeinberg equilibrium and they are consistent with those observed in Caucasian ethnicity (Archive of Genetic Association Studies accessible at: http://geneticassociationdb.nih.gov/).

No significant association between clinicopathological features and tumour response was found (Table 2). The analysis of the three polymorphisms and response is shown in Table 3. The Bonferroni-adjusted $P$-value for the three comparisons is $0.05 / 3$, $P=0.016$. The $T S 5^{\prime}$-UTR VNTR with $G / C$ polymorphism in $3 R$ alleles showed association with treatment outcome $(P=0.011)$. In particular, high TS expression genotypes $(2 R / 3 G, 3 C / 3 G$ and

Table I Characteristics of the 80 patients and genotype frequencies

\begin{tabular}{|c|c|}
\hline & No. of patients (\%) \\
\hline \multicolumn{2}{|l|}{ Sex } \\
\hline Male & $48(60)$ \\
\hline Female & $32(40)$ \\
\hline \multicolumn{2}{|l|}{ Karnofsky performance status } \\
\hline $90-100$ & $58(72)$ \\
\hline 80 & $22(28)$ \\
\hline \multicolumn{2}{|l|}{ Resected primary tumour } \\
\hline Yes & $70(87)$ \\
\hline No & $10(13)$ \\
\hline \multicolumn{2}{|l|}{ Prior adjuvant therapy } \\
\hline None & $44(55)$ \\
\hline Yes & $36(45)$ \\
\hline \multicolumn{2}{|l|}{ Carcinoembryonic antigen } \\
\hline$\leqslant 10 \mathrm{ngml}^{-1}$ & $56(70)$ \\
\hline$>10 \mathrm{ng} \mathrm{ml}^{-1}$ & $24(30)$ \\
\hline \multicolumn{2}{|l|}{ Genotypes } \\
\hline \multicolumn{2}{|l|}{ TS 5'-UTR VNTR ${ }^{\mathrm{a}}$} \\
\hline $2 R / 2 R$ & $16(20)$ \\
\hline $2 R / 3 R$ & $38(47)$ \\
\hline $3 R / 3 R$ & $26(33)$ \\
\hline \multicolumn{2}{|l|}{ TS 5'-UTR VNTR+G/Cb } \\
\hline $2 R / 2 R, 2 R / 3 C, 3 C / 3 C$ & $48(60)$ \\
\hline $2 R / 3 G, 3 C / 3 G, 3 G / 3 G$ & $32(40)$ \\
\hline \multicolumn{2}{|l|}{ TS 3'-UTR } \\
\hline$-6 /-6$ & $30(38)$ \\
\hline$-6 /+6$ & $40(50)$ \\
\hline$+6 /+6$ & $10(12)$ \\
\hline
\end{tabular}

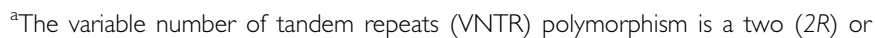
three (3R) 28-bp tandem repeat sequence in TS $5^{\prime}$-UTR. ${ }^{b} \mathrm{~A}$ single-nucleotide change in $3 R$ allele is a second polymorphism that distinguishes $3 G$ carriers $(2 R / 3 G, 3 G / 3 G$ and $3 G / 3 C$ genotypes) from non-3G carriers (2R/2R, $2 R / 3 C$ and $3 C / 3 C$ genotypes). 
Table 2 Characteristics of the patients and tumour response

No. of patients (\%)

\begin{tabular}{|c|c|c|c|c|}
\hline Characteristics & No. of patients (\%) & $\operatorname{Responders}^{\mathrm{a}}(\mathrm{N}=34)$ & Non-responders ${ }^{a}(N=46)$ & $P$-value \\
\hline $90-100$ & $58(72)$ & $26(76)$ & $32(70)$ & 0.6 \\
\hline 80 & $22(28)$ & $8(24)$ & $14(30)$ & \\
\hline \multicolumn{5}{|c|}{ Resected primary tumour } \\
\hline Yes & $67(84)$ & $30(88)$ & $37(80)$ & 0.5 \\
\hline No & $13(16)$ & $4(12)$ & $9(20)$ & \\
\hline Yes & $36(45)$ & $13(38)$ & $23(50)$ & \\
\hline \multicolumn{5}{|c|}{ Carcinoembryonic antigen } \\
\hline$\leqslant 10 \mathrm{ng} \mathrm{ml}^{-1}$ & $56(70)$ & $26(76)$ & $30(65)$ & 0.4 \\
\hline$>10 \mathrm{ng} \mathrm{ml}^{-1}$ & $24(30)$ & $8(24)$ & $16(35)$ & \\
\hline
\end{tabular}

${ }^{a}$ Responders are patients with complete or partial response. Non-responders are patients with stable disease or disease progression.

Table 3 Association between genotypes and response to chemotherapy in the 80 patients

\begin{tabular}{|c|c|c|c|c|}
\hline \multirow[b]{2}{*}{ Genotypes } & \multirow[b]{2}{*}{$\begin{array}{c}\text { No. of } \\
\text { patients (\%) }\end{array}$} & \multicolumn{2}{|c|}{ No. of patients (\%) } & \multirow[b]{2}{*}{$P$-value } \\
\hline & & $\begin{array}{l}\text { Responders }^{a} \\
\quad(N=34)\end{array}$ & $\begin{array}{c}\text { Non-responders }{ }^{a} \\
(N=46)\end{array}$ & \\
\hline \multicolumn{5}{|l|}{ TS 5'-UTR } \\
\hline $2 R / 2 R$ & $16(20)$ & $10(30)$ & $6(13)$ & \\
\hline $2 R / 3 R$ & $38(47)$ & $14(40)$ & $24(52)$ & 0.19 \\
\hline $3 R / 3 R$ & $26(33)$ & $10(30)$ & $16(35)$ & \\
\hline \multicolumn{5}{|l|}{ TS $5^{\prime}-U T R^{\mathrm{b}}$} \\
\hline $\begin{array}{l}2 R / 2 R, 2 R / \\
3 C, 3 C / 3 C\end{array}$ & $48(60)$ & $26(76)$ & $22(48)$ & $0.011^{\S}$ \\
\hline $\begin{array}{l}2 R / 3 G, 3 C / \\
3 G, 3 G / 3 G\end{array}$ & $32(40)$ & $8(24)$ & $24(52)$ & \\
\hline \multicolumn{5}{|l|}{ TS $3^{\prime}-$ UTR } \\
\hline$-6 /-6$ & $30(38)$ & II (32) & $19(4 I)$ & \\
\hline$-6 /+6$ & $40(50)$ & $20(59)$ & $20(44)$ & 0.37 \\
\hline$+6 /+6$ & $10(12)$ & $3(9)$ & $7(15)$ & \\
\hline
\end{tabular}

${ }^{a}$ Responders are patients with complete or partial response. Non-Responders are patients with stable disease or disease progression. ${ }^{b}$ Analysis of the TS $5^{\prime}$-UTR VNTR with $C / G$ nucleotide change in $3 R$ allele carriers. Low-expression genotypes are $2 R /$ $2 R, 2 R / 3 C$ and 3C/3C. High-expression genotypes are 2R/3G, 3G/3G and 3G/3C. ${ }^{\S_{P}}<0.016$ is the level of significance according to the Bonferroni adjustment for three comparisons.

$3 G / 3 G$ ) were found in 8 out of 34 patients with complete or partial response $(23.5 \%)$ and 24 out of 46 patients with stable disease and disease progression (52\%). The $5^{\prime}$-UTR VNTR and the $3^{\prime}$-UTR 6 -bp insertion/deletion $(6+/ 6-)$ did not show association with tumour response. To further evaluate these two variants, their distribution was explored in recessive and additive models also, but without finding significant associations (Table 4).

The TS $5^{\prime}$-UTR and TS $3^{\prime}$-UTR loci showed mild LD $\left(r^{2}=0.17\right)$. As shown in Table 5, non-3G haplotypes were prevalent in responders and $3 G$ haplotypes in non-responders, with significantly different distribution of the 3G/6- haplotype.

Eleven responsive patients underwent liver surgery for resection of the residual metastatic disease (13.7\%). Clear resection margins with removal of all known metastatic lesions were attained in these patients, with 10 of them carrying one of the low TS expression genotypes $(2 R / 2 R, 2 R / 3 C$ and $3 C / 3 C)$. At the time of data analysis (March 2008), 78 patients suffered from disease progression
Table 4 Association between genotypes and response to chemotherapy in additive and recessive models

\begin{tabular}{|c|c|c|c|c|}
\hline \multirow[b]{2}{*}{ Genotypes } & \multirow[b]{2}{*}{$\begin{array}{c}\text { No. of } \\
\text { patients (\%) }\end{array}$} & \multicolumn{2}{|c|}{ No. of patients (\%) } & \multirow[b]{2}{*}{$P$-value } \\
\hline & & $\begin{array}{l}\text { Responders }^{a} \\
\quad(N=34)\end{array}$ & $\begin{array}{l}\text { Non-responders }{ }^{a} \\
(N=46)\end{array}$ & \\
\hline \multicolumn{5}{|l|}{$T S 5^{\prime}-U T R$} \\
\hline \multicolumn{5}{|l|}{ Recessive model } \\
\hline $2 R / 2 R, 2 R / 3 R$ & $54(67)$ & $24(70)$ & $30(65)$ & 0.63 \\
\hline $3 R / 3 R$ & $26(33)$ & $10(30)$ & $16(35)$ & \\
\hline \multicolumn{5}{|l|}{ TS 5'-UTR } \\
\hline \multicolumn{5}{|l|}{ Additive model } \\
\hline $2 R / 2 R$ & $16(20)$ & $10(30)$ & $6(13)$ & 0.09 \\
\hline $2 R / 3 R, 3 R / 3 R$ & $64(80)$ & $24(70)$ & $40(87)$ & \\
\hline \multicolumn{5}{|l|}{ TS 3'-UTR } \\
\hline \multicolumn{5}{|l|}{ Recessive model } \\
\hline $\begin{array}{l}-6 /-6 \\
-6 /+6\end{array}$ & $70(87)$ & $31(9 \mid)$ & $39(85)$ & 0.50 \\
\hline$+6 /+6$ & $10(13)$ & $3(9)$ & $7(15)$ & \\
\hline \multicolumn{5}{|l|}{ TS 3'-UTR } \\
\hline$-6 /-6$ & $30(38)$ & II (32) & $19(4 I)$ & 0.48 \\
\hline $\begin{array}{l}-61+6 \\
+6+6\end{array}$ & $50(62)$ & $23(68)$ & $27(59)$ & \\
\hline
\end{tabular}

${ }^{a}$ Responders are patients with complete or partial response. Non-responders are patients with stable disease or disease progression.

(97.5\%). For addressing an exploratory analysis of time to progression in patients with high and low TS expression genotypes, time to event distributions were studied using the Kaplan-Meier method. As shown in Figure 1, the results support the influence of the TS $5^{\prime}$-UTR VNTR with G/C SNP on the outcome of these patients.

\section{DISCUSSION}

To the best of our knowledge, this is the first analysis of TS polymorphisms in patients with liver-only MCRC. In comparison with previous studies (Pullarkat et al, 2001; Etienne et al, 2002; 
Table 5 Distribution of estimated haplotype frequencies according to treatment outcome

\begin{tabular}{lccl}
\hline Haplotype & Non-responders (\%) & Responders (\%) & $\chi^{\mathbf{2}}$ \\
\hline $2 R / 6-$ & 7.3 & 9.7 & 0.3 \\
$2 R / 6+$ & 32.5 & 41.3 & 0.06 \\
$3 \mathrm{Cl6}-$ & 8.9 & 9.6 & 0.7 \\
$3 \mathrm{Cl6}+$ & 16.3 & 19.9 & 0.2 \\
$3 \mathrm{G} / 6-$ & 26.2 & 16.9 & 0.01 \\
$3 \mathrm{G} / 6+$ & 6.2 & 5.2 & 0.5 \\
\hline
\end{tabular}

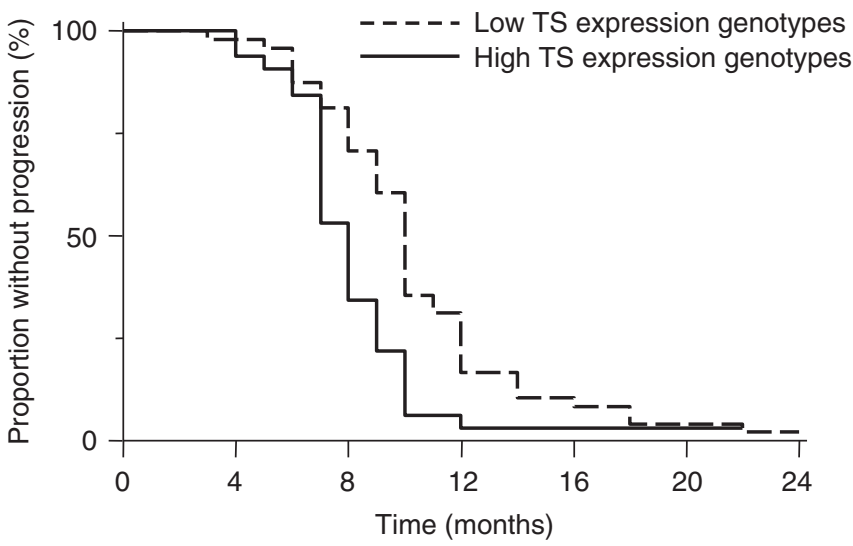

Figure I Kaplan-Meier analysis of time to progression (TTP) in patients with low TS expression genotypes $(2 R / 2 R, 2 R / 3 C$ and $3 C / 3 C)$ and high TS expression genotypes (2R/3G, 3C/3G and $3 G / 3 G)$. TTP was calculated from the start of chemotherapy to the first evidence of disease progression. Two patients who underwent resection of liver metastases were progressionfree at the time of analysis (one with a low TS expression genotype and the other with a high TS expression genotype). $\chi^{2}$ of the log-rank test $=10.4$ $(P=0.001)$.

Park et al, 2002; Lecomte et al, 2004; Marcuello et al, 2004; Stoehlmacher et al, 2004; Jakobsen et al, 2005; Martinez-Balibrea et al, 2007; Ruzzo et al, 2007a, b), we evaluated a homogeneous and low-burden disease population that was exposed to the same regimen of 5-fluorouracil including both bolus and infusional administration of the drug (Hoshino et al, 2005).

Heterogeneity in clinical features in patients with metastatic disease (Sorbye et al, 2007) may represent a major limitation for observing actual pharmacogenetic effects of functional germline polymorphisms. Notably, the number of metastatic sites plays a relevant prognostic role in patients with metastatic colorectal cancer (Köhne et al, 2002), and differences in clinical outcomes can be observed between patients with different metastatic sites (Köhne et al, 2002). The planning of this study was also motivated by the fact that colorectal cancer commonly metastasises to the liver, and such a single-organ involvement, instead of a multisite metastatic disease, can accurately be monitored during chemotherapy for the assessment of response (Trillet-Lenoir et al, 2002). Low-burden metastatic disease may also limit the impact of heterogeneity in molecular/genetic alterations as they accumulate during tumour progression and metastatisation (Yokota, 2000). Loss of heterozygosity ( $\mathrm{LOH}$ ) is to be included among these possible genetic changes. Owing to LOH at the TS locus on chromosome 18 in cancer cells, carriers of the germline heterozygous $2 R / 3 R$ genotype can acquire the $2 R /$ loss genotype in their tumours (Kawakami et al, 2002; Uchida et al, 2004a, b). Therefore, the lower responsiveness of germline $2 R / 3 R$ carriers could not be displayed because heterozygous patients with tumour $2 R / l o s s$ genotype behave as $2 R / 2 R$ patients (Uchida et al, 2004a, b). This phenomenon implies that responsiveness to 5-fluorouracil-based therapy may depend on the tumour rather than on the germline status of the genotypes (Uchida et al, 2004a, b). However, our findings suggest that the double assessment of the VNTR plus G/C nucleotide change with dichotomisation of patients into carriers of high $(2 R / 3 G, 3 C / 3 G$ and $3 G / 3 G)$ and low $(2 R / 2 R, 2 R / 3 C$ and $3 C / 3 C)$ TS expression genotypes may not suffer from the possible presence of LOH. The finding of the association between TS $5^{\prime}$-UTR $\mathrm{VNTR}+\mathrm{G} / \mathrm{C}$ and tumour response may not only reflect a better functional characterisation of $3 C$ and $3 G$ alleles, but also a less extensive influence of tumour $\mathrm{LOH}$ on the germline assessment for high-TS expression genotypes $(2 R / 3 G, 3 C / 3 G$ and $3 G / 3 G)$.

In our opinion, TS polymorphisms deserved the present investigation more than other genetic variants with putative influence on 5-fluorouracil activity (i.e. methylenetetrahydrofolate reductase gene polymorphisms). In addition to the fact that TS is the target enzyme of 5-fluorouracil, it has been observed that TS levels may be dynamic, with upregulation after fluoropyrimidine exposure (Uchida et al, 2004a, b; Mauritz et al, 2007). In particular, this effect was described in liver metastases from colorectal cancer in patients who received bolus 5-fluorouracil (Mauritz et al, 2007). Therefore, TS polymorphisms may influence the outcome to 5-fluorouracil chemotherapy, not only for their role in determining different baseline levels of TS activity (Marsh, 2005), but also for modulating the enhancement of TS levels in response to 5-fluorouracil. In fact, the 5-fluorouracil-induced upregulation of TS mRNA may be greater in carriers of high-expression TS genotypes than in carriers of low-expression TS genotypes. We cannot rule out, however, that a double assessment of TS and methylenetetrahydrofolate reductase polymorphisms may improve the predictive role of the single analysis of TS polymorphisms.

Another reason for studying pharmacogenetics in liver-only MCRC patients is related to the lack of predictive factor for response to neoadjuvant chemotherapy. Liver surgery can provide long-term survival for liver-only, metastatic colorectal cancer patients, but liver metastasectomy is feasible in only $15-25 \%$ of the patients. Neoadjuvant chemotherapy can provide response rates as high as $50 \%$, allowing liver metastasectomy in about $10-15 \%$ of patients initially deemed unresectable. Tumour response to preoperative chemotherapy seems to be associated with outcome following liver resection for colorectal metastases (Folprecht et al, 2005) and, if genetically predictable, it could be improved by the selective choice of available drugs. In this study, 10 of the 11 responsive patients who underwent liver surgery were carriers of low TS expression genotypes $(2 R / 2 R, 2 R / 3 C$ and $3 C / 3 C)$. Actually, we performed an analysis of TS polymorphisms for response to 5-fluorouracil and we did not address this study to pharmacogenetics for liver metastases resectability and survival after preoperative chemotherapy. These end points require a prospective study, including a baseline multidisciplinary evaluation of the unresectable liver disease and long-term follow-up.

In conclusion, the homogeneous subgroup of patients with liver-only metastatic disease allowed the predictive role of TS polymorphisms to stand out. In fact, the association between polymorphisms and tumour response was included in the secondary end points of our two previous pharmacogenetic studies (Ruzzo et al, 2007a, b), but these analyses failed to demonstrate a predictive role for the genetic variants. The clinical setting assumes a relevant role for exploring the pharmacogenetic associations in patients with metastatic cancer and additional studies are warranted for confirming our findings.

\section{ACKNOWLEDGEMENTS}

We thank the Consorzio Interuniversitario per le Biotecnologie (CIB) and Fanoateneo for financial support. 


\section{REFERENCES}

Calascibetta A, Cabibi D, Martorana A, Sanguedolce G, Rausa L, Feo S, Dardanoni G, Sanguedolce R (2004) Thymidylate synthase gene promoter polymorphisms are associated with TSmRNA expressions but not with microsatellite instability in colorectal cancer. Anticancer Res 24: $3875-3880$

Colucci G, Gebbia V, Paoletti G, Giuliani F, Caruso M, Gebbia N, Cartenì G, Agostara B, Pezzella G, Manzione L, Borsellino N, Misino A, Romito S, Durini E, Cordio S, Di Seri M, Lopez M, Maiello E, Montemurro S, Cramarossa A, Lorusso V, Di Bisceglie M, Chiarenza M, Valerio MR, Guida T, Leonardi V, Pisconti S, Rosati G, Carrozza F, Nettis G, Valdesi M, Filippelli G, Fortunato S, Mancarella S, Brunetti C, Gruppo Oncologico Dell'Italia Meridionale (2005) Phase III randomized trial of FOLFIRI versus FOLFOX4 in the treatment of advanced colorectal cancer: a multicenter study of the Gruppo Oncologico Dell'Italia Meridionale. J Clin Oncol 23: $4866-4875$

Etienne MC, Chazal M, Laurent-Puig P, Magné N, Rosty C, Formento JL, Francoual M, Formento P, Renée N, Chamorey E, Bourgeon A, Seitz JF, Delpero JR, Letoublon C, Pezet D, Milano G (2002) Prognostic value of tumoral thymidylate synthase and p53 in metastatic colorectal cancer patients receiving fluorouracil-based chemotherapy: phenotypic and genotypic analyses. J Clin Oncol 20: 2832-2843

Folprecht G, Grothey A, Alberts S, Raab HR, Köhne CH (2005) Neoadjuvant treatment of unresectable colorectal liver metastases: correlation between tumour response and resection rates. Ann Oncol 16: 1311-1319

Horie N, Aiba H, Oguro K, Hojo H, Takeishi K (1995) Functional analysis and DNA polymorphism of the tandemly repeated sequences in the 5 -terminal regulatory region of the human gene for thymidylate synthase. Cell Struct Funct 20: $191-197$

Hoshino S, Yamashita Y, Maekawa T, Shirakusa T (2005) Effects on DNA and RNA after the administration of two different schedules of 5-fluorouracil in colorectal cancer patients. Cancer Chemother Pharmacol 56: $648-652$

Jakobsen A, Nielsen JN, Gyldenkerne N, Lindeberg J (2005) Thymidylate synthase and methylenetetrahydrofolate reductase gene polymorphism in normal tissue as predictors of fluorouracil sensitivity. J Clin Oncol 2: $1365-1369$

Kawakami K, Ishida Y, Danenberg KD, Omura K, Watanabe G, Danenberg PV (2002) Functional polymorphism of the thymidylate synthase gene in colorectal cancer accompanied by frequent loss of heterozygosity. Jpn J Cancer Res 93: 1221 - 1229

Kawakami K, Omura K, Kanehira E, Watanabe Y (1999) Polymorphic tandem repeats in the thymidylate synthase gene is associated with its protein expression in human gastrointestinal cancers. Anticancer Res 19: $3249-3252$

Kawakami K, Watanabe G (2003) Identification and functional analysis of single nucleotide polymorphism in the tandem repeat sequence of the thymidylate synthase gene. Cancer Res 63: 6004-6007

Köhne CH, Cunningham D, Di CF, Glimelius B, Blijham G, Aranda E, Scheithauer W, Rougier P, Palmer M, Wils J, Baron B, Pignatti F, Schöffski P, Micheel S, Hecker H (2002) Clinical determinants of survival in patients with 5-fluorouracil-based treatment for metastatic colorectal cancer: results of a multivariate analysis of 3825 patients. Ann Oncol 13: $308-317$

Lecomte T, Ferraz JM, Zinzindohoué F, Loriot MA, Tregouet DA, Landi B, Berger A, Cugnenc PH, Jian R, Beaune P, Laurent-Puig P (2004) Thymidylate synthase gene polymorphism predicts toxicity in colorectal cancer patients receiving 5-fluorouracil-based chemotherapy. Clin Cancer Res 10: $5880-5888$

Mandalà M, Mosconi S, Quadri A, Milesi L, Labianca R (2007) Neoadjuvant chemotherapy for patients with liver metastases from colorectal cancer. Exp Rev Anticancer Ther 7: 887-897

Mandola MV, Stoehlmacher J, Muller-Weeks S, Cesarone G, Yu MC, Lenz HJ, Ladner RD (2003) A novel single nucleotide polymorphism within the $5^{\prime}$ tandem repeat polymorphism of the thymidylate synthase gene abolishes USF-1 binding and alters transcriptional activity. Cancer Res 63: $2898-2904$

Mandola MV, Stoehlmacher J, Zhang W, Groshen S, Yu MC, Iqbal S, Lenz HJ, Ladner RD (2004) A 6 bp polymorphism in the thymidylate synthase gene causes message instability and is associated with decreased intratumoral TS mRNA levels. Pharmacogenetics 14: 319-327

Marcuello E, Altés A, del Rio E, César A, Menoyo A, Baiget M (2004) Single nucleotide polymorphism in the $5^{\prime}$ tandem repeat sequences of thymidylate synthase gene predicts for response to fluorouracil-based chemotherapy in advanced colorectal cancer patients. Int J Cancer 112: $733-737$

Marsh S (2005) Thymidylate synthase pharmacogenetics. Invest New Drugs 23: $533-537$

Martinez-Balibrea E, Manzano JL, Martinez-Cardus A, Moran T, Cirauqui B, Catot S, Taron M, Abad A (2007) Combined analysis of genetic polymorphisms in thymidylate synthase, uridine diphosphate glucoronosyltransferase and X-ray cross complementing factor 1 genes as a prognostic factor in advanced colorectal cancer patients treated with 5-fluorouracil plus oxaliplatin or irinotecan. Oncol Rep 17: 637-645

Mauritz R, van Groeningen CJ, Smid K, Jansen G, Pinedo HM, Peters GJ (2007) Thymidylate synthase and dihydropyrimidine dehydrogenase mRNA expression after administration of 5-fluorouracil to patients with colorectal cancer. Int J Cancer 120: 2609-2612

Morganti M, Ciantelli M, Giglioni B, Putignano AL, Nobili S, Papi L, Landini I, Napoli C, Valanzano R, Cianchi F, Boddi V, Tonelli F, Cortesini C, Mazzei T, Genuardi M, Mini E (2005) Relationships between promoter polymorphisms in the thymidylate synthase gene and mRNA levels in colorectal cancers. Eur J Cancer 41: 2176-2183

Park DJ, Stoehlmacher J, Zhang W, Tsao-Wei D, Groshen S, Lenz HJ (2002) Thymidylate synthase gene polymorphism predicts response to capecitabine in advanced colorectal cancer. Int J Colorectal Dis 17: 46-49

Popat S, Matakidou A, Houlston RS (2004) Thymidylate synthase expression and prognosis in colorectal cancer: a systematic review and meta-analysis. J Clin Oncol 22: 529-536

Pullarkat ST, Stoehlmacher J, Ghaderi V, Xiong YP, Ingles SA, Sherrod A, Warren R, Tsao-Wei D, Groshen S, Lenz HJ (2001) Thymidylate synthase gene polymorphism determines response and toxicity of 5-FU chemotherapy. Pharmacogenomics J 1: 65-70

Ruzzo A, Graziano F, Loupakis F, Rulli E, Canestrari E, Santini D, Catalano V, Ficarelli R, Maltese P, Bisonni R, Masi G, Schiavon G, Giordani P, Giustini L, Falcone A, Tonini G, Silva R, Mattioli R, Floriani I, Magnani M (2007a) Pharmacogenetic profiling in patients with advanced colorectal cancer treated with first-line FOLFOX-4 chemotherapy. J Clin Oncol 25: $1247-1254$

Ruzzo A, Graziano F, Loupakis F, Santini D, Catalano V, Bisonni R, Ficarelli R, Fontana A, Andreoni F, Falcone A, Canestrari E, Tonini G, Mari D, Lippe P, Pizzagalli F, Schiavon G, Alessandroni P, Giustini L, Maltese P, Testa E, Menichetti ET, Magnani M (2007b) Pharmacogenetic profiling in patients with advanced colorectal cancer treated with first-line FOLFIRI chemotherapy. Pharmacogenomics J 8(4): 278-288

Sorbye H, Köhne CH, Sargent DJ, Glimelius B (2007) Patient characteristics and stratification in medical treatment studies for metastatic colorectal cancer: a proposal for standardization of patient characteristic reporting and stratification. Ann Oncol 18: 1666-1672

Stoehlmacher J, Park DJ, Zhang W, Yang D, Groshen S, Zahedy S, Lenz HJ (2004) A multivariate analysis of genomic polymorphisms: prediction of clinical outcome to 5-FU/oxaliplatin combination chemotherapy in refractory colorectal cancer. Br J Cancer 91: 344-354

Therasse P, Arbuck SG, Eisenhauer EA, Wanders J, Kaplan RS, Rubinstein L, Verweij J, Van Glabbeke M, van Oosterom AT, Christian MC, Gwyther SG (2000) New guidelines to evaluate the response to treatment in solid tumors. European Organization for Research and Treatment of Cancer, National Cancer Institute of the United States, National Cancer Institute of Canada. J Natl Cancer Inst 92: 205-216

Trillet-Lenoir V, Freyer G, Kaemmerlen P, Fond A, Pellet O, LombardBohas C, Gaudin JL, Lledo G, Mackiewicz R, Gouttebel MC, Moindrot H, Boyer JD, Chassignol L, Stremsdoerfer N, Desseigne F, Moreau JM, Hedelius F, Moraillon A, Chapuis F, Bleuse JP, Barbier Y, Heilmann MO, Valette PJ (2002) Assessment of tumour response to chemotherapy for metastatic colorectal cancer: accuracy of the RECIST criteria. Br J Radiol 75: $903-908$

Uchida K, Hayashi K, Kawakami K, Schneider S, Yochim JM, Kuramochi H, Takasaki K, Danenberg KD, Danenberg PV (2004a) Loss of heterozygosity at the thymidylate synthase (TS) locus on chromosome 18 affects tumor response and survival in individuals heterozygous for a 28-bp polymorphism in the TS gene. Clin Cancer Res 10: 433-439

Uchida K, Hayashi K, Kuramochi H, Takasaki K (2004b) Changes in intratumoral thymidylate synthase (TS) and dihydropyrimidine dehydrogenase (DPD) mRNA expression in colorectal and gastric cancer during continuous tegafur infusion. Int J Oncol 19: $341-346$

Ulrich CM, Bigler J, Velicer CM, Greene EA, Farin FM, Potter JD (2000) Searching expressed sequence Tag databases: discovery and confirma- 
tion of a common polymorphism in the thymidylate synthase gene. Cancer Epidemiol Biomarkers Prev 9: 1381-1385

Yawata A, Kim SR, Miyajima A, Kubo T, Ishida S, Saito Y, Nakajima Y, Katori N, Matsumoto Y, Fukuoka M, Ohno Y, Ozawa S, Sawada J (2005) Polymorphic tandem repeat sequences of the tymidylate gene correlates with cellular-based sensitivity to fluoropyrimidine antitumor agents. Cancer Chemother Pharmacol 56: 465-472
Yokota J (2000) Tumor progression and metastasis. Carcinogenesis 21: $497-503$

Yong WP, Innocenti F (2007) Translation of pharmacogenetic knowledge into cancer therapeutics. Clin Adv Hematol Oncol 5: 698-706

Yu KH, Wang WX, Ding YM, Li H, Wang ZS (2008) Polymorphism of thymidylate synthase gene associated with its protein expression in human colon cancer. World J Gastroenterol 14: 617-621 